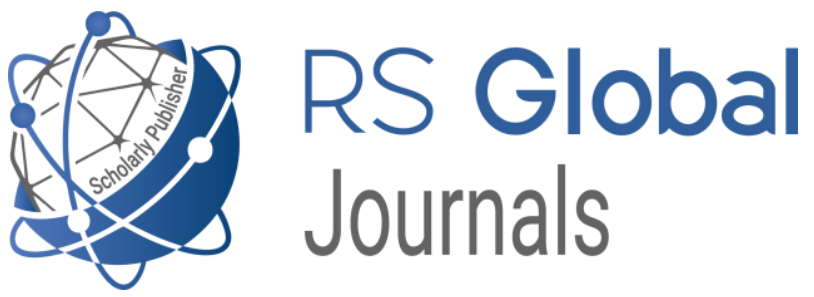

Scholarly Publisher RS Global Sp. z O.O. ISNI: 0000000484952390

Dolna 17, Warsaw, Poland 00-773

Tel: +48226022703

Email: editorial_office@rsglobal.pl

\begin{tabular}{ll} 
JOURNAL & Science Review \\
\hline p-ISSN & $2544-9346$ \\
\hline e-ISSN & $2544-9443$ \\
\hline PUBLISHER & RS Global Sp. z O.O., Poland
\end{tabular}

ARTICLE TITLE

РОЛЬ ТЕХНИЧЕСКОГО ПИСЬМА И ПИСАТЕЛЯ ПРИ РАЗРАБОТКЕ ДОКУМЕНТАЦИИ К ПРОЕКТУ

$\operatorname{AUTHOR}(\mathbf{S})$

Бакунов А. М., Бакунова О. М., Александрович А. Ф., Владысик М. С., Мелешкевич Д. В., Ситник М. Ю.

Bakunov Alexander, Bakunova Oksana, Aleksandrovich Aryna, Vladysik Maksim, Meliashkevich Daniil, Sitnik Maksim. (2020)

ARTICLE INFO Role of Technical Letter and Writer in Development of Project Documentation. Science Review. 6(33). doi: 10.31435/rsglobal_sr/30092020/7190

DOI https://doi.org/10.31435/rsglobal_sr/30092020/7190

RECEIVED 27 July 2020

ACCEPTED 10 September 2020

PUBLISHED 15 September 2020

LICENSE

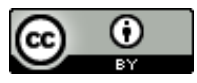

This work is licensed under a Creative Commons Attribution 4.0 International License.

(C) The author(s) 2020. This publication is an open access article. 


\section{РОЛЬ ТЕХНИЧЕСКОГО ПИСЬМА И ПИСАТЕЛЯ ПРИ РАЗРАБОТКЕ ДОКУМЕНТАЦИИ К ПРОЕКТУ}

Бакунов А. М., магистр технических наук, ст. преподаватель БГУИР, Беларусь

Бакунова О. М., магистр технических наук, исследователь технических наук, cm. преподаватель БГУИР, Беларусь

Александрович $А$. Ф., технический писатель, ООО "Е-ком Технологии", Беларусь

Владысик М. С., техник группы радиосвязи, ГААСУ МЧС Авиащия, Беларусь

Мелешкевич Д. В., системный администратор, ОАО "МТЗ" "Медицинский центр МТЗ",

Беларусь

Ситник М. Ю., Инженер-программист, ООО "РАЙЗИНГ", Беларусь

DOI: https://doi.org/10.31435/rsglobal_sr/30092020/7190

\section{ARTICLE INFO}

Received 27 July 2020

Accepted 10 September 2020

Published 15 September 2020

\section{KEYWORDS}

technical writer, specialist, IT field, development, innovation, technical documentation, professional tasks.

\begin{abstract}
Innovations in the field of technology have had a great impact on public development and have made life more comfortable and safer. In recent decades, the world community has entered an era of digitalization. Modern technology has helped many to make travel more accessible to the whole world. The development of IT technologies has led to the simplification of calculations, both in scientific and everyday life. It is difficult to imagine a modern person who would not have a smartphone. Personal information that synchronizes with all our devices. In any modern smartphone you can meet a smart assistant. Smart columns appear, at home, cars controlled by artificial intelligence.
\end{abstract}

Citation: Bakunov Alexander, Bakunova Oksana, Aleksandrovich Aryna, Vladysik Maksim, Meliashkevich Daniil, Sitnik Maksim. (2020) Role of Technical Letter and Writer in Development of Project Documentation. Science Review. 6(33). doi: 10.31435/rsglobal_sr/30092020/7190

Copyright: (C) 2020 Bakunov Alexander, Bakunova Oksana, Aleksandrovich Aryna, Vladysik Maksim, Meliashkevich Daniil, Sitnik Maksim. This is an open-access article distributed under the terms of the Creative Commons Attribution License (CC BY). The use, distribution or reproduction in other forums is permitted, provided the original author(s) or licensor are credited and that the original publication in this journal is cited, in accordance with accepted academic practice. No use, distribution or reproduction is permitted which does not comply with these terms.

Введение. Сфера IT является активным инновационным развивающимся пространством, которое характеризуется использованием результатов своей деятельности. В современной практике под компетенцией понимают - способность применять знания, умения, успешно действовать на основе практического опыта при решении задач общего рода, а также в определенной широкой области. Основными требованиями IT компаний по разработкам ПО к специалистам являются:

- умение оперативно решать типовые и нестандартные профессиональные задачи;

- компетентность;

- творческий подход;

- культуру мышления;

- самостоятельный поиск знаний, недостающих для решения задачи.

В такую команду входят следующие специалисты - руководитель проекта, менеджер проекта, бизнес-аналитик, постановщик, технический писатель, программист, тестировщик. В этой статье более подробно рассмотрим специалиста по техническому написанию документации.

Результаты и обсуждение. Технических писателей характеризуют два важных навыка это способность понимать технологии и способность объяснять сложные процессы простым языком с ясностью. Им также приходится работать с различными иностранными языками. Перевод должен быть выполнен очень точно. Это также означает отказ от творчества. 
Технические писатели, которые документируют различные области, такие как производство, электроника и медицина. Компании предпочитают нанимать выпускников инженерных, естественных или английских специальностей. Обязательным является знание и комфорт работы с различными инструментами.

Технические писатели документируют интерактивную справку, примечания к выпуску, руководства по установке и настройке, руководства по рабочему процессу и сопутствующую документацию для продукта. Они используют продукт, взаимодействуют с инженерами, чтобы понять его, и, наконец, пишут контент, чтобы объяснить различные аспекты, связанные с ним. Созданный ими контент проверяется командой специалистов.

Писатели также просматривают пользовательский интерфейс, ярлыки и различные сообщения об ошибках. На данном этапе работы основная роль технического писателя состоит в том, чтобы проверять содержание, отображаемое в пользовательском интерфейсе на предмет грамматической точности, а также давать предложения с точки зрения удобства использования. Знания в области разработки ценятся, и работа с инструментами, поддерживающими DITA, определенно является преимуществом.

Технический писатель всегда думает с точки зрения пользователя и документировать информацию, полезную для клиента. Иногда они участвуют в создании видеороликов для конкретной задачи или в создании диаграмм / визуальных элементов, которые помогут покупателю лучше понять продукт.

Технический писатель добавляет ценность к продукту. Если писатель создает документ, потому что «заказчик этого ожидает» или «это входит в бюджет и план», то весь смысл будет упущен. Технический писатель должен осознавать и понимать, задаваться вопросом: «Добавляет ли это (документ, изменение, дополнение и другое) ценность?» на каждом этапе развития. Можно даже представить себе ситуацию, когда документ нужно удалить, чтобы повысить ценность. Таким образом, помимо написания статьи, технические писатели должны знать о содержании, структуре, доступе, потребностях клиентов, формате, планах обучения, собеседованиях и многом другом. Чтобы повысить ценность продукта, нужна общая картина.

Каждый проект технического письма начинается с исследования. Это может показаться очевидным, но знание цели и объема технической документации заранее сэкономит массу времени и энергии. Если технический писатель не является экспертом в предметной области, это может создать определенные трудности в работе с проектом, начиная от проведения некоторых внутренних собеседований и заканчивая налаживанием отношений с технической командой, для лучшего понимания материала.

Вся эта информация содержится в так называемом плане документации - кратком плане, который поможет в работе над проектом. Часто задаваемые вопросы:

Основные вопросы, которые формируются в цели:

1. Что мы хотим, чтобы люди могли делать для использования продукта? Как найти справочные документы, быстро и легко? Как использовать определенные аспекты инструмента?

2. Есть ли четкое понимание целей, необходимых для написания качественной технической документации?

3. Существующие ресурсы: Что сейчас доступно? Обновляем или объединяем текущие ресурсы или начинаем с нуля? Есть другие, устаревшие версии, которые нужно удалить? Сделать быстрый аудит и найти все, что поможет описать или не запутать аудиторию, если они это найдут.

4. Руководства по стилю: в некоторых отраслях требуется писать техническую документацию определенным образом (например, рекомендации на простом языке для государственных сайтов или упрощенный технический английский для аэрокосмических, авиационных или оборонных компаний). В таких случаях у компании может быть руководство по стилю, в котором объясняется, какой язык использовать, как разговаривать с пользователями и даже грамматические стили.

5. Краткое описание тем: какие темы и подтемы охватим в своей технической документации?

6. Инструменты и управление: какое программное обеспечение, инструменты или вебсайты будут использоваться для создания документации и управления ею? Ссылка на соответствующие руководства по стилю. 
7. Крайний срок и окончательные результаты: когда проект должен быть и в каком формате он будет? Техническая документация касается не только содержания, но и структуры и доставки. И зная, как контент будет представлен до того, как начнется разработка документа, поймем, что нужно и куда приложить усилия.

Цель любой технической документации - пригодность использования. И во многом это делает её структурно логичной и простой в навигации. Прежде чем начать создавать контент, нужно подумать о том, как этот контент будет представлен. Техническая документация - это структурированный контент. Чтобы он был полезным, он должен быть представлен таким образом, чтобы его можно было быстро проанализировать и найти то, что нужно.

Это означает, что нужно продумать как дизайн страницы (как выглядят отдельные технические документы, что в них включено и иерархию информации), так и структуру навигации документа (в каком порядке представлена информация, как перемещаются пользователи по навигации, какие документы связаны или не связаны и т. д.). В большинстве случаев это означает использование какого-либо шаблона или схемы (схемы построения данных).

Выводы. Техническая документация должна быть проста в использовании, эффективна, содержать актуальную информацию, единый дизайн и быть доступной.

\section{ЛИТЕРАТУРА}

1. Бакунов А.М., Бакунова О.М., Калитеня И.Л., Образцова О.Н. Применение ИКТ в образовательном процессе специальности «Программное обеспечение информационных технологий» специализации «Программное обеспечение обработки экономической и деловой информации» / Подготовка специалиста-профессионала в различных видах деятельности: [электронный ресурс]: материалы Республиканской научно-практической конференции с международным участием, Гомель, 23-24 ноября 2017 г. - Гомель: Гомельский областной институт развития образования, 2017. - С. 43 - 46.

2. О. М. Бакунова, О. Н. Образцова, Силинский, Р. А. Дистанционные технологии как способ оптимизации трудовых процессов инженеров испытательной лаборатории // Дистанционное обучение - образовательная среда XXI века: материалы X международной научно-методической конференции (Минск, 7 - 8 декабря 2017 года). - Минск: БГУИР, 2017. - С. 286.

3. Бакунова О. М., Калитеня И. Л., Бакунов А. М., Малиновская Т.И. Применение ИКТ для оказания образовательных услуг лицам с особыми потребностями на примере изучения системы $1 \mathrm{C}$ дистанционно // Непрерывное профессиональное образование лиц с особыми потребностями: сборник статей международной науч.-практической конференции (Минск, 14 - 15 декабря 2017 года). - Минск: БГУИР, 2017. - С. $41-43$.

4. Бакунова О. М., Калитеня И. Л., Бакунов А. М., Антонов Е. Д., Мелешкевич Д.В. Информационные компьютерные сети и системы в сфере образования // Непрерывное профессиональное образование лиц с особыми потребностями: сборник статей международной науч.-практической конференции (Минск, 14 - 15 декабря 2017 года). - Минск: БГУИР, 2017. - С. 39 - 41.

5. Бакунова О. М., Калитеня И. Л., Бакунов А. М., Нарижный, Е. Ю., Образцова О.Н. Внедрение мобильного по в качестве методического пособия для обучения лиц с особыми потребностями // Непрерывное профессиональное образование лиц с особыми потребностями: сборник статей международной науч.-практической конференции (Минск, 14 - 15 декабря 2017 года). - Минск: БГУИР, 2017. - С. $38-39$.

6. Бакунова О. М., Калитеня И. Л., Бакунов А. М., Палуйко А. Ф., Антонов Е. Д.,Гречко И. С. Использование нейронных сетей в образовании. INTERNATIONAL ACADEMY JOURNAL Web of Scholar 1(19), Vol.1, - Warsaw, Poland, 2018 C. 8 - 11

7. Бакунова О. М., Хмелевская А.Л., Беликов А. С., Мирончик А. Н., Агапкин Л.М., Чучвал А.Ю. Использование современных подходов и нейронных сетей для качественного образования в ВУЗах // I Международный симпозиум "Гуманитарные и общественные науки в Европе: достижения и перспективы" - Вена, Австрия 2018 г. 